\title{
OS CONTOS INFANTIS NAS SÉRIES INICIAIS: UMA BREVE CONTEXTUALIZAÇÃO
}

\author{
Jaqueline de Souza Oliveira ${ }^{1}$, Eraldo Carlos Batista ${ }^{2}$, Dayane Fernandes Ferreira ${ }^{3}$
}

\begin{abstract}
Resumo: Os contos infantis nas séries iniciais têm como benefício, entre outros, o incentivo à formação do hábito de leitura na infância, melhoria nas relações sociais e na relação professor/aluno. Além disso, estimula o desenvolvimento das funções cognitivas importantes para o pensamento. Sob esse viés, o objetivo deste artigo foi contextualizar os benefícios que os contos infantis proporcionam no desenvolvimento afetivo, emocional, intelectual e na aprendizagem da criança nas séries iniciais. O método utilizado foi a pesquisa bibliográfica a partir de produções indexadas em bibliotecas virtuais e materiais impressos. Como conclusão, destaca-se que os contos infantis proporcionam à criança a possibilidade de aprender de forma divertida e que o ato de ler um conto torna-se a prática da leitura mais agradável, interessante e motivadora para as crianças nas séries iniciais. Além disso, possibilita a construção coletiva de histórias e auxilia a criança a se relacionar com os outros e a resolver os problemas do mundo real.
\end{abstract}

Palavras-chave: Conto infantil. Leitura. Desenvolvimento cognitivo. Imaginação.

\section{FAIRYTALES IN INITIAL GRADES: A BRIEF CONTEXTUALIZATION}

\begin{abstract}
Fairy tales in initial grades can benefit, among other qualities, the encouragement of reading habits during the childhood, improvement in social relations and on the relation student/teacher. Besides, it also stimulates the development of important cognitive functions for thinking. Under this bias, the objective of this research was to contextualize the benefits that fairy tales can provide in the development of affective, emotional, and intellectual qualities, as well as in the learning of children in early grades. The methodology used was a literature review from productions indexed in virtual libraries and in printed materials. As conclusion, we highlight that fairy tales provide to children the possibility of learning in a fun way, and that the act of reading fairy tales turns the practice of reading more pleasant, interesting and a motivation for children in initial grades. Furthermore, it allows the collective construction of stories and assists the kid in relating to others and to solve real world problems.
\end{abstract}

Keywords: Fairy tale. Reading. Cognitive development. Imagination.

1 Licenciada em Pedagogia. E-mail: prof-jacke30@outlook.com

2 Mestre em Psicologia pela Universidade Federal de Rondônia - UNIR, Docente da Faculdade São Paulo-FSP.E-mail: eraldo.cb@hotmail.com

3 Bacharel em Psicologia, Especialista em Docência do Ensino Superior. Docente da Faculdade São Paulo-FSP. E-mail: psicologadayane2015@hotmail.com 


\section{INTRODUÇÃO}

Na cultura ocidental, contar ou ouvir histórias é um hábito milenar primordial entre os humanos. $\mathrm{Na}$ antiguidade, os povos se reuniam ao redor da fogueira e narravam suas lendas e contos, disseminando a sua cultura e os seus costumes. Essas lendas e contos eram histórias do imaginário popular pertencentes à memória coletiva, destinadas a ouvintes, adultos e crianças, que não sabiam ler (SOUZA; BERNARDINO, 2011).

Assim, ouvir e contar histórias reveste-se de inúmeros significados; esse hábito está interligado ao desenvolvimento da imaginação, à capacidade de ouvir e de se expressar, à construção de identidade e aos cuidados afetivos. $O$ primeiro contato da criança com as histórias acontece no ambiente familiar através dos contos de fada, das histórias bíblicas, das histórias inventadas e tantas outras apresentadas oralmente pelos pais ou irmãos mais velhos, mas é na vida escolar que esse contato se intensifica.

A escola se constitui como principal espaço para o desenvolvimento das habilidades de ouvir e contar histórias. Essa prática contribui para o desenvolvimento do senso crítico e da autonomia individual da criança e do grupo, aproximando-os do universo da leitura e escrita, ampliando o vocabulário e estimulando o imaginário.

Dentre os vários tipos de histórias que são utilizados para contar histórias, elegeram-se neste estudo, os contos infantis como objeto de contextualização na prática de leitura no contexto escolar. Os contos infantis são narrativas que, geralmente, possuem uma problemática ética, espiritual e existencial, ligada à realização interior do indivíduo, as quais, basicamente por intermédio do amor, giram em torno de deuses, heróis, duendes ou situações em que o sobrenatural acaba se destacando.

Os contos despertam a imaginação e a curiosidade da criança que quase sempre é respondida no decorrer da narração, oral ou escrita, permitindo a aquisição de conhecimento em diversos níveis. Sendo assim, narrar um conto para crianças é possibilitar a ela a realização de conquistas, no mínimo, nos planos pedagógico, histórico, psicológico, cultural, social e estético (COELHO, 2003; MACHADO, 2002).

Nas séries iniciais, o conto infantil pode ser usado como ferramenta para o desenvolvimento do gosto pela leitura, uma vez que ele ajuda a melhorar a comunicação e as relações sociais, formando grupos de novos leitores. Dessa forma, o conto cria as bases necessárias para que a criança se torne um leitor que busca o livro para adquirir conhecimento e ao mesmo tempo se divertir.

Sabe-se que o ato de ler se dá em vários momentos, entre os quais se destaca a diversão durante a leitura. $\mathrm{O}$ conto infantil tem essa característica, de agradar a criança, possibilitando-lhe vivenciar, no seu imaginário, experiências que lhe acompanharão por toda a sua vida. Em outras palavras, pode-se afirmar que a formação do leitor passa pela atividade inicial do escutar e do recontar histórias (SOUZA; BERNARDINO, 2011). 
Com base nesses pressupostos, o problema que move o presente estudo é a discussão sobre a importância do resgate e da manutenção da capacidade imaginativa da criança por meio dos contos infantis. Considerando essas questões, o objetivo deste artigo é contextualizar os benefícios que o conto infantil proporciona ao desenvolvimento cognitivo, no gosto pela leitura, nas relações interpessoais e na criatividade da criança.

\section{METODOLOGIA}

Para alcançar os objetivos propostos nesse estudo, foi desenvolvida uma pesquisa bibliográfica do tipo exploratória que, segundo Gil (2008), constitui-se da releitura de um determinado tema a partir de livros e artigos científicos. Sendo assim, as fontes utilizadas foram dissertações e teses, artigos científicos e livros. Na busca do material para elaboração do artigo, utilizaram-se os seguintes descritores: contos infantis, contos de fadas, literatura infantil, leitura, conto nas séries iniciais, contos e aprendizagem, conto e desenvolvimento infantil.

\section{OS CONTOS DE FADAS PARA A FORMAÇÃO DA CRIANÇA}

As mudanças ocorridas na sociedade nos últimos tempos têm modificado os seus costumes. Com os avanços tecnológicos contemporâneos, as pessoas têm cada vez mais substituído o livro pelos aparelhos eletrônicos. Com isso, poucas famílias têm mantido o hábito de contar histórias para as crianças na hora de dormir e essa atividade foi dando lugar a outros interesses. O que parece é que a percepção que se tem de contos infantis é de algo antigo, ultrapassado pelas inovações da modernidade.

A razão para tal pensamento pode estar relacionada às mudanças das formas de apresentação dos contos às crianças. Os melhores contos infantis foram perpetuados por gerações, muitos transformados em obras literárias, depois em quadrinhos e mais recentemente em películas de cinema e da televisão. No seu enredo, elementos humanos como o ódio, a inveja, o ciúme, a ambição, a rejeição e a frustração são abordados e, ao final, sempre se exaltam as qualidades desejadas na pessoa humana através das personagens principais. Em uma leitura crítica, pode-se dizer que se apresenta à criança o modelo comportamental do cidadão que se espera dela (CADEMARTÓORI, 1986).

Entretanto, o conto não é uma narrativa reta. A riqueza de detalhes das personagens, do ambiente social em que vivem, o seu status, enfim, exigem que a criança realize uma contextualização imaginária, divertida, instigante e pessoal. Assim, quando um grupo de crianças conta ou ouve um conto, cada uma faz a sua leitura, apresentando uma riqueza de detalhes individualizada, mesmo que seja a mesma história, contada no mesmo local e para crianças com a mesma idade. Isso se deve ao fato de que cada criança possui sentimentos e emoções próprios e sua leitura de mundo se opera através deles (SILVA; BARROS; NASCIMENTO, 2012). 
Tal como nos séculos anteriores, o fascínio que as histórias exercem sobre as pessoas não mudou, pois, quando se conta uma história, lança-se um fio invisível que vai enredando o narrador ao ouvinte pelas tênues tramas da narração. Por isso, a importância da preferência de contar histórias para a criança a outras formas de apresentação. Contar histórias como Chapeuzinho Vermelho, Rapunzel, Cinderela, ou Lobo Mau, por serem agradáveis, faz com que a criança as preserve intactas em sua memória. Talvez, o hábito de contar e ouvir histórias tenha sido a razão pela qual os contos ficaram preservados na memória social coletiva desde muito antes da descoberta da escrita (CADERMATÓRI, 1986).

Outro fator a ser mencionado é que o encantamento que a narrativa dos contos gera sobre a criança tem natureza lúdica e lhe proporciona a condição de deixar aflorar os sentimentos, as emoções e, no final, o sorriso. Esse aspecto retira a criança da rotina da vida diária, do cumprimento de ordens e realização de seus deveres para dar a liberdade necessária de, divertindo-se, imaginar e construir cenários (SILVA; BARROS; NASCIMENTO, 2012).

Nesse caso, pode-se dizer que, quando a criança pede ao pai, à mãe ou ao educador que lhe repita um determinado conto, com o qual criou afinidade, demonstra está tentando revisar conceitos e reforçar sua estrutura emocional, podendo trabalhar no campo da realidade sobre esses aspectos tratados posteriormente (PIRES, 2000).

Os personagens do conto, sobretudo o herói, ocupam um lugar especial no imaginário das crianças, mesmo naquelas que ainda não possuem discernimento sobre todas as atitudes do personagem. Sobre isso, Souza et al. (2008) afirmam que as crianças pequenas, que se identificam com o herói, o fazem para se ligarem a sua pessoa e não propriamente à qualidade que representa (bondade, por exemplo), o que só acontecerá com o desenvolvimento cognitivo e afetivo.

Acrescente-se que, nas suas histórias, a criança normalmente assume o papel do protagonista, ou seja, do herói:

Herói é o personagem que vive grandes aventuras e consegue vencer todos os problemas que surgem à sua volta. Por isso ele é considerando o personagem principal, cujas ações, pensamentos e sentimentos acompanhamos com maior interesse. O herói é também chamado protagonista da história. Nem sempre o herói é um personagem com qualidades positivas. Existem heróis que são atrapalhados, malandros e vivem grandes situações de embaraço, mas continuam sendo protagonistas. Estes são conhecidos como anti-heróis (MACHADO, 1994, p. 45).

Dessa forma, é na representação de viver o herói que a criança vai se tornando independente e cada vez mais orientada para o futuro.

Só partindo para o mundo é que o herói dos contos de fada (a criança) pode se encontrar; e fazendo-o, encontrará também o outro com quem será capaz de viver feliz para sempre; isto é, sem nunca mais ter de experimentar a ansiedade de 
separação. O conto de fadas é orientado para o futuro e guia a criança - em termos que ela pode entender tanto na sua mente inconsciente quanto consciente - a ao abandonar seus desejos de dependência infantil e conseguir uma existência mais satisfatoriamente independente (BETTELHEIM, 2007, p. 19).

Essas práticas permitem que a criança crie suas histórias, ganhe habilidades na construção de textos e desenvolva sua capacidade inventiva, além, é claro, de capacitarse para enfrentar os problemas de mundo.

\section{OS CONTOS INFANTIS E O DESENVOLVIMENTO COGNITIVO DA CRIANÇA}

O conto tem como característica chamar, conscientemente ou não, a criança a refletir sobre o comportamento dos personagens. A capacidade de abstração que a criança vai desenvolvendo permite que ela se articule para melhor resolver os dilemas que enfrentará na vida real, sejam eles interiores ou exteriores.

Não é à toa que o enredo dos contos infantis é permeado de conteúdos simbólicos que atuam sobre o emocional da criança induzindo ao amadurecimento. O mote "Era uma vez..." chama a criança a entrar em um mundo do imaginário, viver sua experiência pessoal, reflexionar sobre a conduta das personagens. Todo esse processo intelectivo internalizado se transformará em estruturas mentais que a ajudarão a resolver suas próprias inquietudes (ABRAMOVICH, 1997).

A mesma autora ainda acrescenta que, muito embora no imaginário se trabalhe com fantasias desprendidas da realidade, isso não impede que se aproveite a estrutura construída e ajude a criança a compreender porque precisa respeitar os pais, as normas sociais, o seu colega e assim por diante. Ou seja, os enredos ajudam a fortalecer a construção de sua personalidade, a compreensão de que precisa lutar pelo seu espaço social, o que inclui seus direitos (ABRAMOVICH, 1997).

Isso se dá a partir da compreensão da criança de que as coisas que acontecem nos contos não são apenas dádivas, apesar de seu componente mágico, e que os personagens precisam estudar, treinar e trabalhar, para que o desfecho seja aquele desejado. Ao perceber que até seus heróis precisam se esforçar, a criança é induzida a também reflexionar que precisa estar interessada para que seu aprender permita chegar, no mundo real, próximo ao idealizado no conto. Em outras palavras, "Sem o passaporte mágico, dessas narrativas, é difícil conceber viagens, aventuras, temores, medos e receios imaginários fundamentais ao nosso desenvolvimento intelectual e emocional" (CHALITA, 2003, p. 10).

Outro aspecto que precisa ser ressaltado é que o domínio de emoções e sentimentos é trabalhado internamente, no subconsciente da criança e, nesse sentido entende-se que: 
Para dominar os problemas psicológicos do crescimento - separar decepções narcisistas, dilemas edípicos, rivalidades fraternas, ser capaz de abandonar dependências infantis; obter um sentimento de individualidade e de autovalorização, e um sentido de obrigação moral - a criança necessita entender o que se está passando dentro de seu eu inconsciente. Ela pode atingir essa compreensão, e com isto a habilidade de lidar com as coisas, não através da compreensão racional da natureza e conteúdo de seu inconsciente, mas familiarizando-se com ele através de devaneios prolongados - ruminando, reorganizando e fantasiando sobre elementos adequados da estória em resposta a pressões inconscientes. Com isto, a criança adequa o conteúdo inconsciente às fantasias conscientes, o que a capacita a lidar com este conteúdo (BETTELHEIM, 2007, p. 16).

Ou seja, é por meio das histórias infantis que a criança aprende que a vida humana é repleta de acontecimentos, e que a maioria desses acontecimentos não depende da vontade da pessoa. Isso significa dizer que cada indivíduo precisa estar apto a atuar contra dificuldades, dissabores, alegrias, conquistas, perdas, e que todas se constituem em um processo natural para o amadurecimento do ser humano.

Como exemplo a ser ilustrado, pode-se pensar no que acontece com a personagem heroica que passa o conto inteiro lutando por aquilo que lhe é de direito, sofrendo, e no capítulo final tem reconhecido seu direito e passa vivê-lo em sua plenitude. Para Farias e Rubio (2012), é fundamental que a criança compreenda que terá de conviver com dificuldades, que a vida tem muitas alegrias, mas apresenta momento de dissabores, que não são eternos e, no tempo certo e com esforço, podem ser superados.

É certo que se vive em um mundo no qual a tecnologia, principalmente a da informação, tem ocasionado a redução das publicações impressas, pela preferência àquelas ferramentas como o computador, os tablets e os smartphones, além das películas televisivas e cinematográficas, mas o ato de ler como processo de construção de estruturas cognitivas e afetivas, ainda preserva a primazia, pois "Através do livro e da leitura, a humanidade pode divinizar-se, homens e mulheres podem ser deuses, porque imantados pelas verdades expostas nas escrituras" (PERROTTI, 1990, p. 39). Não é outra a percepção, portanto, a de que por meio da leitura o ser humano ganha outra dimensão, viajando, inventando, transformando, enfim, essa divinização o torna criador de realidades imaginárias.

\section{A APRENDIZAGEM E OS CONTOS}

Como mencionado anteriormente, o hábito diário da leitura de contos pela e para a criança tem demonstrado ser um importante mecanismo para desenvolver o gosto pela leitura. Também já se sabe que a boa leitura, em termos pedagógicos, é aquela que permite a reflexão. Assim, o conto infantil escrito permite a criança ler, ouvir e interpretar as mensagens que são transmitidas através do enredo. $O$ conto infantil narrado pelo professor ou outro aluno ajuda a desenvolver a audição e, ao mesmo tempo, abstrair-se, imaginar o cenário e as ações que lhe são transmitidas. 
Quando o conto é apresentado através de recurso audiovisual, a criança se transporta para aquele cenário, mas em seu desenvolvimento intelectual, seja qualquer a forma como o conto chega a ela, é nítida a contribuição que oferece ao processo de compreensão do mundo e, como o fio condutor da história são palavras, também ocorre o enriquecimento de seu vocabulário e aumenta a capacidade de comunicação (RADINO, 2003).

Portanto, entende-se que a literatura infantil pode influenciar na formação da criança, que passa a conhecer e a compreender o mundo em que vive. Como destaca Goes (1993, p. 16), “a leitura para a criança não é, como às vezes se ouve, meio de evasão ou apenas compensação. É um modo de representação do real. Através de um 'fingimento', o leitor reage, reavalia, experimenta as próprias emoções e reações”. Ao se contemplar essa afirmativa, vê-se como a leitura e a sua utilização pode promover condições de aprendizagem e relaxamento, buscando um aprendizado fluente.

Em acréscimo, vale lembrar que a os enredos presentes nos contos são elaborados a partir das ideologias e intencionalidades do adulto, de modo que, em suma:

[..] 'o livro infantil', se bem que dirigido à criança, é de invenção e intenção do adulto. Transmite os pontos de vista que este considera mais úteis à formação de seus leitores. E transmite-os na linguagem e no estilo que adulto igualmente crê adequados à compreensão e ao gosto do seu público (MEIRELES, 2016, p. 29).

Nesse sentido, pode-se afirmar que o conto infantil não é algo desligado ou menos importante que a literatura para adultos; possui importância igual ou maior, tanto que:

[...] a literatura infantil vem sendo criada, sempre atenta ao nível do leitor a que se destina [...] e consciente de que uma das mais fecundas fontes para a formação dos imaturos é a imaginação - espaço ideal da literatura. É pelo imaginário que o eu pode conquistar o verdadeiro conhecimento de si mesmo e do mundo em que lhe cumpre viver (COELHO, 2000, p. 141).

No campo da pedagogia infantil, é possível verificar que as histórias infantis podem ser traduzidas como oportunidades de vivências imaginárias de atividades que permitem aplicações interdisciplinares durante o processo de alfabetização, tornando as aulas menos cansativas, ou repetitivas, sem perder o interesse da criança que busca novidades. Em complemento ao que foi postulado, Pinto (2004) remete que o conto permite ensinar divertindo e, com conteúdos interdisciplinares foge-se à linearidade, ainda autorizando que a criança interaja emocional e sentimentalmente em relação ao que está sendo narrado e não seja apenas expectadora passiva.

Como já foi mencionado, o conto também pode ser abordado nos aspectos da criação individual e coletivo. Através da familiaridade com os enredos dos contos que abordam valores sociais, as crianças se sentem instigadas a inventarem histórias que sugerem temas importantes para a sua formação humana como o preconceito, os valores 
morais e éticos, os sentimentos, a religião e cultura de paz, a alimentação, a higiene, enfim, temas com os quais se tem contato diariamente. A criança, então, segundo Pinto (2004), passa a narrar a sua interpretação de realidade de mundo e deixa de ser agente passivo para ser agente proativo, atuando para a sua transformação.

Nessa perspectiva, pode-se reconhecer que:

As pessoas aprendem a ler antes de serem alfabetizadas, desde pequenos, somos conduzidos a entender um mundo que se transmite por meio de letras e imagens. O prazer da leitura, oriundo da acolhida positiva e da receptividade da criança, coincide com um enriquecimento íntimo, já que a imaginação dela recebe subsídios para a experiência do real, ainda quando mediada pelo elemento de procedência fantástica (ZILBERMAN, 1995, p. 107).

Desse modo, a criança que vivencia muitas histórias está construindo sua alfabetização para além do ato de ler. Aprende a interpretar os significados que o texto possui explicitamente e aqueles que estão nas entrelinhas.

Outra característica do conto infantil é sua capacidade de melhorar a qualidade da relação professor/aluno. Sabe-se que nem sempre essa relação é constituída ou se dá de forma harmoniosa. Uma vez que a perspectiva da criança, em relação ao professor, culturalmente encontra-se sedimentada na subordinação de autoridade,

[...] na prática pedagógica, podem surgir entre professor e aluno, sentimentos de atração ou de repulsão. Essas atitudes sentimentais têm o poder de influenciar a metodologia com risco de alterá-la, provocando no aluno, rudes transformações afetivas mais ou menos desfavoráveis ao ensino. O poder do professor é maior que o do livro, e a qualidade do diálogo estabelecido entre professor e aluno é importante para uni-los, criando um laço especial, ou para separá-los, criando obstáculos intransponíveis (MARCHAND, 1985, p. 19).

No entanto, esse diálogo na relação pode ser estabelecido e mediado por meio dos contos infantis, ao proporcionar aos poucos a aproximação e a criação de laços de afetividade e compreensão mútua, o que reforçará a qualidade do trabalho do professor e a colaboração da criança. Nessa direção, Pinto $(2004$, p. 109) afirma que não se deve perder a perspectiva de que "uma criança é capaz de interpretar uma história é capaz de codificar símbolos e significados ligados aos fatos do seu cotidiano, e a afetividade faz parte destes signos, uma vez que o cognitivo e o afetivo estão interligados".

Há que se recordar, ainda, que as escolas brasileiras e o ato de ler, a apresentação dos contos como possibilidade de leitura e aprendizagem, sempre se deram através de uma ligação "quase" que umbilical.

Fora da escola, sob a orientação dos professores e com o acompanhamento dos pais, o conto é a possibilidade de a criança expandir seu domínio de leitura, de comunicação verbal e de internalização de processos cognitivos. Sem perder a perspectiva de que: 
É à literatura, como linguagem e como instituição, que se confiam os diferentes imaginários, as diferentes sensibilidades, valores e comportamentos através dos quais uma sociedade expressa e discute, simbolicamente, seus impasses, seus desejos, suas utopias. Por isso a literatura é importante no currículo escolar: o cidadão, para exercer, plenamente sua cidadania, precisa apossar-se da linguagem literária, alfabetizar-se nela, tornar-se seu usuário competente, mesmo que nunca vá escrever um livro: mas porque precisa ler muitos (LAJOLO, 2008, p. 106).

Por outro lado, não se pode perder a perspectiva da ludicidade dos contos infantis. A noção de como é agradável para a criança o ato de leitura, a audição e a visualização do conto infantil, que sempre se apresenta revestido de caráter lúdico. Nesse diapasão, é preciso lembrar sempre de que "[...] a literatura infantil é também ludismo, é fantasia, é questionamento, e dessa forma consegue ajudar a encontrar respostas para as inúmeras indagações do mundo infantil, enriquecendo no leitor a capacidade de percepção das coisas" (FRANTZ, 2001, p. 16).

Quanto se reporta a importância da criança com os contos infantis, recorda-se que:

A criança é criativa e precisa de matéria-prima sadia, e com beleza, para organizar seu 'mundo mágico', seu universo possível, onde ela é dona absoluta: constrói e destrói. Constrói e cria, realizando tudo o que ela deseja. A imaginação bem motivada é uma fonte de libertação, com riqueza. É uma forma de conquista de liberdade, que produzirá bons frutos, como a terra agreste, que se aduba e enriquece, produz frutos sazonados (CARVALHO, 1989, p. 21).

Fica evidente que o conto possui uma função lúdica junto à criança, mas pedagogicamente cumpre, também, importante papel no desenvolvimento das estruturas afetivas e cognitivas; ao proporcionar a experiência no campo imaginário, ajuda no desenvolvimento e amadurecimento da criança que, ao se defrontar com problemas na realidade de mundo em que está inserida, já possui uma tábua de valores internalizada, sendo capaz de refletir sobre conduta e tomada de decisão.

Em suma, são inúmeros os benefícios dos contos infantis na formação da criança, como melhoria na leitura e, quando esses são trabalhados na oralidade, podem melhorar a articulação das palavras, a segurança da criança em se comunicar com o professor, com os colegas, pais e demais pessoas, melhorando também a escrita quando a criança reproduz ou cria seus próprios contos.

Portanto, o conto é importante para o desenvolvimento da criança e deve estar presente na educação infantil, pois essa ferramenta prepara a criança em todos os níveis intelectivos e psicológicos para exercer a sua cidadania, por meio das experiências no plano imaginário. 


\section{CONSIDERAÇÕES FINAIS}

Neste estudo, objetivou-se enfatizar a importância dos contos infantis como um caminho que leva a criança a desenvolver a imaginação, as emoções e os sentimentos de forma prazerosa e significativa. Buscou-se explicar de maneira breve, a contextualização histórica dos contos ao longo do tempo e como ganharam novas formas de serem apresentados às crianças na contemporaneidade com o uso de novas tecnologias.

Foi possível entender que nos contos o encantamento não vem a priori pela identificação da criança com a representação das qualidades (bondade, gratidão, amor) do herói, mas sim com a ligação a sua pessoa.

Assim, foi possível compreender que trabalhar com os contos infantis é algo de fundamental no processo do desenvolvimento da aprendizagem das crianças, porque favorece a socialização e o desenvolvimento das suas habilidades e criatividades. E que o conto possibilita vantagens de agradar mais ao gosto das crianças pela sua ludicidade sem que se perca a possibilidade de desenvolvimento da comunicação verbal e escrita, da interpretação e do estabelecimento de relações sociais, ao mesmo tempo em que ajuda na formação das estruturas mentais.

As histórias infantis, lidas pelo professor ou pelas próprias crianças, possibilitam nestas últimas, a experiência de estados afetivos, emocionais e psicológico que modificam sua forma de pensar e ver o mundo, pois o universo do imaginário da criança é como um mundo paralelo em que vão sendo acrescidos aqueles valores e condutas desejáveis no mundo real.

O conto ainda tem um papel fundamental na mediação estratégica da qualidade da relação professor/aluno. O trabalho do professor nesse contexto será a escolha de contos infantis que se adequem à idade e ao interesse das crianças, bem como a presença dos valores que pretenda refletir. Enfim, a sensibilidade e o conhecimento do professor irá determinar a melhor escolha. Uma boa técnica que pode ser utilizada é incentivar a criança a realizar a leitura do conto para seus pais, irmãos ou pessoas próximas. Assim, à medida que se valoriza seu interesse, a criança se mostra disposta a conhecer e interpretar outras realidades desse seu mundo imaginário.

\section{REFERÊNCIAS}

ABRAMOVICH, F. Por uma arte de contar histórias. São Paulo: Scipione, 1997.

BETTELHEIM, B. A psicanálise dos Contos de Fadas. 22 ed. Rio de Janeiro: Paz e Terra, 2007.

CADEMARTORI, L. O que é literatura infantil. 2. ed. São Paulo: Brasiliense 2010.

CARVALHO, B. V. A literatura infantil: visão histórica e crítica. 6. ed. São Paulo: Global, 1989. 
CHALITA, G. Pedagogia do Amor. A contribuição das histórias universais para à formação de valores da nova geração. São Paulo: Gente, 2003.

COELHO, N. N. Literatura infantil: teoria analise didática. 6. ed. São Paulo. Moderna, 2003.

FARIAS, F. R. A.; RUBIO, J. A. S. Literatura infantil: a contribuição dos contos de fadas para a construção do imaginário infantil. Revista Eletrônica Saberes da Educação, v. 3, n. 1, 2012. Disponível em: <http://www.facsaoroque.br/novo/publicacoes/pdf/v3-n1-2012/francy. pdf >. Acesso em: 04 mai. 2015.

FRANTZ, M. H. Z. O ensino da literatura nas séries iniciais. 3 ed. Ijuí/RS: UNIJUI, 2001.

GIL, A. C. Métodos e técnicas de pesquisa social, 6. ed. São Paulo: Atlas, 2008.

GOES, L. P. A aventura da literatura para crianças. São Paulo: Melhoramentos, 1993.

LAJOLO, M. Do mundo da leitura para a leitura do mundo. 6 ed. São Paulo: Ática, 2008.

MACHADO, A. M. Como e porque ler os clássicos universais desde cedo. Rio de Janeiro, Objetiva, 2002.

MACHADO, I. A. Literatura e redação. São Paulo: Scipione, 1994

MARCHAND, M. A afetividade do educador. São Paulo: Summus, 1985.

MEIRELES, C. Problemas da literatura infantil. 4. ed. Rio de Janeiro: Nova Fronteira, 2016.

PERROTTI, E. Confinamento cultural, infância e leitura. São Paulo: Summus, 1990.

PIRES, D. H. O. “livro... Eterno livro...” Belo Horizonte, UFMG, 2000.

PINTO, F. E. M. Por detrás dos seus olhos: a afetividade na organização do raciocínio humano. Campinas, 2004.

RADINO, Glória. Contos de fadas e a realidade psíquica: A importância da fantasia no desenvolvimento. Assis: Casa do Psicólogo, 2003.

SILVA, M. A. L.; BARROS, R. B.; NASCIMENTO, T. A. M. A importância dos contos de fadas na educação infantil. Campina Grande: Realize, 2012.

SOUSA, L. O.; BERNARDINO, A. A contação de história como estratégia pedagógica na Educação Infantil e Ensino Fundamental. Revista de Educação, v. 6, n. 12, p. 235249, 2011. Disponível em: <http://e-revista.unioeste.br/index.php/educereeteducare/article/ view/4643/4891>. Acesso em: 01 set. 2016

SOUZA, M. T. C. C. et al. Relações entre aspectos afetivos e cognitivos em representações de contos de fadas. Boletim de Psicologia, v. 58, n. 129, p. 227-242, 2008. Disponível em: <http://pepsic.bvsalud.org/pdf/bolpsi/v58n129/v58n129a10.pdf>. Acesso em: 02 set. 2016.

ZILBERMAN, R. Literatura infantil: livro, leitura, leitor. In: . (Org.) A produção cultural para a criança. Porto Alegre: Mercado Aberto, 1995, p. $91-115$. 